\title{
Preference for Artemisinin-based combination therapy among healthcare providers, Lokoja, North-Central Nigeria
}

Sylvanus C. Welle $e^{1,2^{*}}$, Olufemi Ajumobi ${ }^{2,3}$, Magbagbeola Dairo ${ }^{4}$, Muhammad Balogun ${ }^{2,3}$, Peter Adewuyi ${ }^{5}$, Babatunde Adedokun ${ }^{4}$, Patrick Nguku ${ }^{2,3}$, Saheed Gidado ${ }^{2,3}$ and IkeOluwapo Ajayi ${ }^{2,4}$

\begin{abstract}
Background: In Nigeria, Artemisinin-based Combination Therapy (ACT) is the recommended first line antimalarial medicine for uncomplicated malaria. However, health care providers still continue the use of less efficacious medicines such as Sulphadoxine-pyrimethamine and chloroquine. We therefore determined preference for ACT (PFA) and factors associated with PFA among healthcare providers (HCP) in Lokoja, North-Central Nigeria as well as assessed healthcare providers' knowledge of malaria case management.

Methods: We conducted a cross-sectional study among physicians, nurses, pharmacists, community health officers (CHOs), community health extension workers (CHEWs) and, patent and proprietary medicine vendors (PPMVs). Interviewer-administered questionnaires were administered to collect data on respondents' characteristics, previously received malaria case management training and knowledge of malaria treatment. Knowledge scores $\geq 3$ were categorised as good, maximum obtainable being 5 .

Results: Of the 404 respondents, 214 (53.0\%) were males. Overall, 219 (54.2\%) respondents who received malaria case management training included PPMVs: 79 (65.8\%), CHEWs: 25 (64.1\%), CHOs: 5 (55.6\%), nurses: 72 (48.7\%), physicians: 35 (47.3\%) and pharmacists: 3 (23.1\%). Overall, 202 (50.0\%) providers including physicians: 69 (93.2\%), CHO: 8 (88.9\%), CHEWs: 33 (84.6\%), pharmacists: 8 (61.5\%), nurses: 64 (43.2\%) and PPMVs: 20 (16.5\%), had good knowledge of malaria treatment guidelines. Overall, preference for ACT among healthcare providers was 39.6\%. Physicians: 50 (67.6\%), pharmacists: 7 (59.3\%) CHOs: 5 (55.6\%), CHEWS: 16 (41.0\%), nurses: 56 (37.8\%) and PPMV: 24 (19.8\%) had PFA. Receiving malaria case management training (adjusted odds ratio $[\mathrm{aOR}])=2.3 ; \mathrm{Cl}=1.4-3.7$ ) and having good knowledge of malaria treatment $(\mathrm{aOR}=4.0 ; \mathrm{Cl}=2.4-6.7)$ were associated with PFA.

Conclusions: Overall preference for ACT use was low among health care providers in this study. Preference for ACTs and proportion of health workers with good knowledge of malaria case management were even lower among PPMVs who had highest proportion of those who received malaria case management training. We recommend evaluation of current training quality, enhanced targeted training, follow-up supportive supervision of PPMVs and behavior change communication on ACT use.
\end{abstract}

Keywords: Artemisinin-based combination therapy, Preference for ACT, Healthcare providers

\footnotetext{
* Correspondence: sylvelle2002@yahoo.com

${ }^{1}$ Division of Health Promotion, Department of Family Health, Federal Ministry

of Health, Abuja, Nigeria

${ }^{2}$ Nigeria Field Epidemiology and Laboratory Training Programme, Abuja,

Nigeria

Full list of author information is available at the end of the article
}

(c) The Author(s). 2019 Open Access This article is distributed under the terms of the Creative Commons Attribution 4.0 International License (http://creativecommons.org/licenses/by/4.0/), which permits unrestricted use, distribution, and reproduction in any medium, provided you give appropriate credit to the original author(s) and the source, provide a link to the Creative Commons license, and indicate if changes were made. The Creative Commons Public Domain Dedication waiver (http://creativecommons.org/publicdomain/zero/1.0/) applies to the data made available in this article, unless otherwise stated. 


\section{Background}

In Africa, Artemisinin-based combination therapy remains the medicine of first choice for malaria treatment in most endemic countries. Artemisinin-based combination therapy (ACT) is the most effective medicine against Plasmodium falciparum as resistance to other antimalarial malaria medicines has been reported [1]. In 2005, Nigeria adopted ACT for malaria treatment. Despite this adoption ineffective medicines such as Sulphadoxine-pyrimethamine and chloroquine are still used to treat malaria. Children in South-South (27.0\%) and North-Central (23.0\%) zones are more likely to receive ACT than children in other zones [2, 3].

In Nigeria, it is common knowledge that all cadres of healthcare providers treat malaria. A preliminary survey conducted by the principal investigator in this study showed that records of medicines used in health facilities were poorly kept, trade names of medicines, rather than generic names were written in most cases, thereby making it difficult to ascertain pharmacologic constituents of such medicines. Though ACT is effective in adults and children [4], awareness about the medicine could still be low among healthcare providers [5]. Preference for ACT among healthcare providers is influenced by price and availability of the medicine [6], health facility type [7] and knowledge of recommended antimalarial medicines [8]. Nigerian policy recommends prompt parasitological confirmation by microscopy or rapid diagnostic test (RDT) in all cases of suspected malaria before treatment. In Lokoja, there are no subsidy schemes for ACTs and patients buy ACTs which are readily available in health facilities and patent medicine vendors' shops. Cost of services are similar in private and public health facilities and are paid for out-of-pocket. The purpose of this study was to determine preference for ACT (PFA) and factors associated with PFA among healthcare providers (HCP) in Lokoja, NorthCentral Nigeria, as well as assessed healthcare providers' knowledge of malaria treatment guideline (MTG).

\section{Methods}

\section{Study area}

Lokoja is the capital of Kogi State in North-Central Nigeria [9]. The town has a hot and humid climate with luxuriant vegetation and poor drainage system. These make the environment conducive for breeding of Anopheline mosquitoes and for endemic transmission of plasmodium parasites. In Lokoja Local Government Area, there are 10 primary healthcare centers (PHCs), one secondary health facility (State Specialist Hospital) and a tertiary health facility (Federal Medical Centre). Residents seek treatment for malaria in government-owned primary, secondary and tertiary health facilities, and in shops owned by patent and proprietary medicine vendors (PPMVs). In PHCs, malaria is treated by community health extension workers (CHEWs) and community health officers (CHOs), while physicians do same in secondary health facilities and PPMVs treat malaria in their private shops.

\section{Study design and population}

We conducted a cross sectional survey from March to June 2014 among physicians, pharmacists, nurses, CHEWs, CHOs and PPMVs. Study participants were healthcare providers who had treated malaria for at least 1 year before commencement of the study. Eligible participants who did not consent to the study were excluded.

\section{Sample size calculation}

Sample size of 404 was calculated using a prevalence of $38.5 \%$ [10], precision of $5 \%$ at $95 \%$ confidence interval, assuming a non-response rate of $10 \%$.

\section{Sampling by probability proportional to size (PPS)}

A list of physicians, pharmacists and nurses in Federal Medical Centre and State Specialist Hospital was obtained from the Chief Medical Directors. Lists of CHOs and CHEWs were obtained from the office of the Head of Primary Healthcare Department, Lokoja local government area (LGA), while the list of PPMVs was obtained from the secretary of the association of PPMVs. From a sample frame of $N$ $=914$, the proportion of each cadre was determined. We allocated sample sizes to the cadres using probability proportional to size and then multiplied each proportion by the sample size to ascertain the actual number of respondents per cadre (n). Thereafter, a sampling interval was calculated by dividing "N" with " $\mathrm{N}$ " $(\mathrm{N} / \mathrm{n})$. The first healthcare provider was selected randomly using a table of random numbers and subsequently, every $\mathrm{n}^{\text {th }}$ healthcare provider was selected until the sample size of 404 was completed.

Sampling of health care providers by probability proportional to size (PPS)

\begin{tabular}{|c|c|c|c|c|c|}
\hline $\begin{array}{l}\text { S/ } \\
\text { No. }\end{array}$ & Cadre & $\begin{array}{l}\text { No. in } \\
\text { LGA (N) }\end{array}$ & Proportion & $\begin{array}{l}\text { No. } \\
\text { allocated } \\
\text { (n) }\end{array}$ & $\begin{array}{l}\text { Sampling } \\
\text { Interval, } \\
k=N / n\end{array}$ \\
\hline 1 & Doctors & 155 & $\begin{array}{l}155 / 914 \times \\
404=68\end{array}$ & 68 & 2 \\
\hline 2 & Pharmacists & 32 & $\begin{array}{l}32 / 914 \times \\
404=14\end{array}$ & 14 & 2 \\
\hline 3 & Nurses & 403 & $\begin{array}{l}403 / 914 \times \\
404=178\end{array}$ & 178 & 2 \\
\hline 4 & $\begin{array}{l}\text { Community } \\
\text { Health Officers }\end{array}$ & 8 & $\begin{array}{l}8 / 914 \times \\
404=4\end{array}$ & 4 & 2 \\
\hline 5 & $\begin{array}{l}\text { Community } \\
\text { Health } \\
\text { Extension } \\
\text { Workers }\end{array}$ & 38 & $\begin{array}{l}38 / 914 \times \\
404=17\end{array}$ & 17 & 2 \\
\hline 6 & $\begin{array}{l}\text { Patent Medicine } \\
\text { Vendors }\end{array}$ & 278 & $\begin{array}{l}278 / 914 \times \\
404=123\end{array}$ & 123 & 2 \\
\hline & Total & 914 & & 404 & \\
\hline
\end{tabular}




\section{Data collection}

Data on respondents' socio-demographic characteristics, knowledge of malaria diagnosis and treatment, training on malaria case management, preference for ACTs and possible factors associated with preference for ACTs were collected by trained data collectors using pre-tested semi-structured self-administered paper questionnaires. Respondents who were absent during initial visits were revisited to collect required data.

\section{Outcome measures}

\section{Assessment of knowledge of malaria diagnosis and treatment}

We asked five questions to assess knowledge of malaria diagnosis and treatment among respondents. Correct response to each question was scored 1 and 0 if incorrect. Respondents who answered three or more questions correctly ( $\geq 3$ points) were categorized as having good knowledge while respondents with fewer correct responses were categorized as having poor knowledge. Respondents were asked to name recommended medicines for uncomplicated malaria, malaria in pregnancy, severe malaria and intermittent preventive treatment of malaria in pregnancy. They were also asked to mention two tests for confirmation of suspected malaria cases.

\section{Assessment of preference for ACT}

In the questionnaire, we described scenario of a client with fever who had been diagnosed with uncomplicated malaria. The respondents were requested to write down the name, dosage and duration of medicine they would use to treat such client. Preference for ACT was defined as choice of an ACT for treatment of a case of malaria at any given time.

\section{Assessment of factors associated with preference for ACT}

Literature revealed factors that influenced preference for ACT. We asked questions to determine if such factors influenced healthcare providers' preference for ACT and these factors included: cost of malaria medicines, co-existing illnesses, clients' test results, ease of administration of antimalarials, malaria severity, clients' weight, clients' requests, antimalarials availability, antimalarials advertisement, antimalarials approval status and socio-demographic characteristics of respondents. These factors constituted our independent variables.

\section{Data analysis}

Data were entered, cleaned and analyzed using Epi Info version 7 and summarized using percentages and means. The outcome variable was Preference for ACT (PFA). Chi square test was used to test relationship between categorical variables and outcome variable for bivariate analysis. Factors that were significant at bivariate analysis were further subjected to multivariate analysis (multivariate logistic regression). Results were declared significant at $p$-value $<0.05$.

\section{Assumptions}

We assumed that a healthcare provider who was approached without prior notice to write down name, dosage and duration of medicine he/she regularly uses to treat uncomplicated malaria will give a correct response if he was in habit of treating clients with such medicine. We also assumed that respondents could volunteer such information if assured that their responses would not attract sanctions.

\section{Results}

Socio-demographic characteristics of respondents

The mean age of the respondents was 36.9 years (standard deviation: 9.2 years); 214 (53.0\%) were males and $300(74.4 \%)$ were married. There were more nurses, 148 (36.6\%) and private medicine vendors: 121 (30.0\%) than other cadres while CHOs constituted 2.2\% $(n=9)$ of the respondents. Half, 207 (51.2\%), had treated malaria patients for 5 years or less (Table 1).

\section{Knowledge of malaria case management among respondents}

Half, 202 (50.0\%) of the respondents had good knowledge of malaria case management. By cadre, 69 (93.2\%) physicians, 64 (43.2\%) nurses and 20 (16.5\%) PPMVs had good knowledge of malaria case management. Two hundred and seventy two (67.3\%) respondents knew the recommended medicine for treatment of uncomplicated malaria. Fewer than half $173(43.3 \%)$ of the respondents knew the recommended medicine for malaria in pregnancy. Two thirds 243 (61.1\%) did not know the recommended medicine for treatment of severe malaria. A quarter, 102 (25.3\%) knew the tests for confirmation of suspected malaria and 309 (76.5\%) respondents knew the recommended medicine for intermittent preventive treatment of malaria (Table 2).

\section{Preference for ACT and associated factors}

Overall, 160 (39.6\%) healthcare providers preferred ACT. Physicians: 50 (67.6\%), pharmacists: 7 (59.3\%) CHOs: 5 (55.6\%), CHEWS: 16 (41.0\%), nurses: 56 (37.8\%) and PPMV: 24 (19.8\%) had PFA. We ascertained if certain factors influenced preference for ACT. These factors included cost of malaria medicines, co-existing illnesses, clients' test results, ease of administration of antimalarials, malaria severity, clients' weight, clients' requests, antimalarials availability, antimalarials advertisement, antimalarials approval status and socio-demographic characteristics of respondents. These factors constituted our independent variables. Data were not collected on non-ACTs used for 
Table 1 Socio-demographic characteristics of healthcare providers, Lokoja, Nigeria $(N=404)$

\begin{tabular}{|c|c|c|}
\hline Characteristics & Frequency & Percentage \\
\hline \multicolumn{3}{|c|}{ Age group (years) } \\
\hline $15-24$ & 21 & 5.2 \\
\hline $25-34$ & 167 & 41.3 \\
\hline $35-44$ & 126 & 31.2 \\
\hline $45-54$ & 73 & 18.1 \\
\hline$\geq 55$ & 17 & 4.2 \\
\hline \multicolumn{3}{|l|}{ Sex } \\
\hline Male & 214 & 53.0 \\
\hline Female & 190 & 47.0 \\
\hline \multicolumn{3}{|l|}{ Marital status } \\
\hline Ever Married & 300 & 74.4 \\
\hline Single & 104 & 25.6 \\
\hline \multicolumn{3}{|l|}{ Cadre } \\
\hline Nurses & 148 & 36.6 \\
\hline PMVs & 121 & 30.0 \\
\hline Physicians & 74 & 18.3 \\
\hline CHEWs & 39 & 9.7 \\
\hline Pharmacists & 13 & 3.2 \\
\hline $\mathrm{CHOS}$ & 9 & 2.2 \\
\hline \multicolumn{3}{|c|}{ Length of work experience (years) } \\
\hline $1-5$ & 207 & 51.2 \\
\hline$>5$ & 197 & 48.8 \\
\hline
\end{tabular}

malaria treatment as only trade names of such medicines were documented which made it impossible to ascertain their pharmacological constituents. At bivariate analysis, Being ever married was significantly associated with preference for ACT (Unadjusted OR $=0.4, \mathrm{CI}=0.3-0.7$ ) just as having worked for less than 5 years (Unadjusted OR = $0.4, \mathrm{CI}=0.3-0.7$ ). Physicians were found to be 4.4 times more likely to prefer ACTs than other healthcare providers and the association was statistically significant (Unadjusted $\mathrm{OR}=4.4,95 \% \mathrm{CI}=2.5-7.5$ ) [Table 3].

As shown in Table 4, Healthcare providers whose choice of antimalarials for their patients were influenced by patients' ability to pay for such antimalarials (Unadjusted OR 1.74, CI =1.2-2.6) availability of antimalarials (Unadjusted OR: 2.0, $\mathrm{CI}=1.3-3.9)$ and route of administration of such antimalarials (Unadjusted OR: 2.0, CI $=1.3-3.1$ ) were more likely to prefer ACT. The associations were statistically significant. In addition, those who were trained on case management of malaria (Unadjusted OR: 1.6, CI = 1.0-2.4) and those who had good knowledge (Unadjusted OR: 5.4, $\mathrm{CI}=3.4-8.3$ ) were significantly more likely to prefer ACTs.

\section{Multivariate analysis of factors associated with preference for ACT among healthcare providers, Lokoja}

At multivariate analysis, only two of the factors significant at bivariate analysis remained independently associated with PFA. Healthcare providers trained in malaria case management were twice more likely to prefer ACT than those who were not trained and the association was statistically significant (Adjusted OR $=2.3,95 \% \mathrm{CI}=$ 1.4 - 3.7). Healthcare providers who had good knowledge of malaria diagnosis and treatment were four times more likely to prefer ACT when compared with those without good knowledge (Adjusted OR $=4.0,95 \% \mathrm{CI}=2.4-6.7$ ), see Table 5.

\section{Discussion}

This study was carried out to identify an important gap in the knowledge of case management of malaria and factors that may influence healthcare providers to prefer the recommended antimalarial medicines, ACT. The study had representation of the different cadres of healthcare providers proportionately. The findings are discussed.

\section{Knowledge of malaria case management among respondents}

In this study, the health workers were mostly physicians which is expected as they constituted the highest proportion of healthcare providers in the state. It was only half of the respondents who had overall good knowledge of malaria case management and this was largely contributed to by the physicians as almost all of them (93.2\%) demonstrated good knowledge. This was followed by nurses (43.2\%) and least was PPMVs (16.5\%). The domain the highest proportion of respondents demonstrated correct knowledge was knowing the name of medicine for Intermittent Preventive Treatment (IPT) of malaria in pregnancy (76.5\%) followed by knowing the recommended medicine for treatment of uncomplicated malaria (67.3\%) while the least was knowing the

Table 2 Knowledge of malaria case management among healthcare providers, Lokoja ( $N=404)$

\begin{tabular}{|c|c|c|c|}
\hline S/No. & Knowledge Area & Correct response n (\%) & Incorrect response $\mathrm{n}(\%)$ \\
\hline 1 & Recommended drug for treatment of uncomplicated malaria & $272(67.3)$ & $128(32.7)$ \\
\hline 2 & Recommended drug for treatment of malaria in pregnancy & $173(43.3)$ & $227(56.7)$ \\
\hline 3 & Recommended drug for treatment of severe malaria & $157(38.9)$ & $243(61.1)$ \\
\hline 4 & Confirmatory tests for suspected malaria & $102(25.3)$ & $298(74.7)$ \\
\hline 5 & Recommended drug for intermittent preventive treatment of malaria in pregnancy & $309(76.5)$ & $91(23.5)$ \\
\hline
\end{tabular}


Table 3 Association between socio-demographic characteristics of respondents and Preference for ACT, Lokoja, NorthCentral Nigeria

\begin{tabular}{|c|c|c|c|c|c|}
\hline Characteristics & $\begin{array}{l}\text { No preference for } \mathrm{ACT} N=244 \\
\mathrm{n}(\%)\end{array}$ & $\begin{array}{l}\text { Preference for } A C T N=160 \\
\mathrm{n}(\%)\end{array}$ & $x^{2}$ & Unadjusted OR (95\% CI) & $p$-value \\
\hline \multicolumn{6}{|l|}{ Age group (years) } \\
\hline$<35$ & $118(57.3)$ & $88(42.7)$ & 1.5 & $0.8(0.5-1.1)$ & 0.230 \\
\hline$\geq 35$ & $126(63.4)$ & $72(36.4)$ & & 1 (ref.) & \\
\hline \multicolumn{6}{|l|}{ Sex } \\
\hline Male & $111(58.4)$ & 79 (41.6) & 0.4 & $0.9(0.6-1.3)$ & 0.510 \\
\hline Female & $133(62.1)$ & $81(37.9)$ & & 1 (ref.) & \\
\hline \multicolumn{6}{|l|}{ Marital status } \\
\hline Ever Married & $166(55.3)$ & $134(44.7)$ & 11.68 & $0.41(0.3-0.7)$ & $<0.001$ \\
\hline Single & $78(75.0)$ & $26(25.0)$ & & 1 (ref.) & \\
\hline \multicolumn{6}{|l|}{ Cadre } \\
\hline Non Physicians & $197(67.7)$ & $94(32.3)$ & 29.2 & $4.4(2.5-7.5)$ & $<0.001$ \\
\hline Physicians & $24(32.4)$ & $50(67.6)$ & & 1 (ref.) & \\
\hline \multicolumn{6}{|c|}{ Practice Duration(years) } \\
\hline$<5$ & $120(52.2)$ & $110(47.8)$ & 14.3 & $0.4(0.3-0.7)$ & $<0.001$ \\
\hline$>=5$ & $124(71.3)$ & $50(28.7)$ & & 1 (ref.) & \\
\hline
\end{tabular}

Ref: reference category $=1$

Significant $p$-value $<0.05$

confirmatory test for malaria (25.3\%). The high level of knowledge of IPT could be attributed to the fact that the drug used for IPT, Sulphadoxine-pyrimethanine is a well-known drug among healthcare providers and many of them also provide antenatal care. In addition, the PPMVs stock SP and would be aware of the various uses. The high proportion of those who knew the recommended medicine for treatment of uncomplicated malaria in this study is not surprising as all cadres of healthcare providers engage in treatment for uncomplicated in Nigeria either as healthcare provider or caregiver. On the contrary, diagnosis of malaria is usually done by the laboratory scientists or technicians who were not included in this study. However, the poor knowledge of RDT must have been contributed to by PMMVs although our data was not disaggregated by cadre. Studies have demonstrated high proportion of physicians and formal healthcare workers having correct knowledge of diagnosis [11-13] and poor knowledge among PPMVs [14]

Table 4 Association of patient and human resource related factors with preference for ACT, Lokoja, North-Central Nigeria

\begin{tabular}{|c|c|c|c|c|c|}
\hline Characteristics & $\begin{array}{l}\text { No Preference for ACT, } \\
N=244 \\
\mathrm{n}(\%)\end{array}$ & $\begin{array}{l}\text { Preference for } \mathrm{ACT}, \\
N=160 \\
\mathrm{n}(\%)\end{array}$ & $x^{2}$ & $\begin{array}{l}\text { Unadjusted OR } \\
(95 \% \mathrm{Cl})\end{array}$ & $p$-value \\
\hline Drug treatment influenced by patients' age & $223(59.6)$ & $151(40.4)$ & 0.9 & $1.6(0.7-3.5)$ & 0.360 \\
\hline Drug treatment influenced by patients' weight & $214(59.4)$ & $146(40.6)$ & 0.9 & $1.5(0.8-2.9)$ & 0.340 \\
\hline Malaria severity influenced choice of antimalarial medicine & $206(58.5)$ & $146(41.5)$ & 3.4 & $1.9(1.0-3.7)$ & 0.060 \\
\hline Patients' requests influenced choice of antimalarial medicine & $91(62.8)$ & $54(37.2)$ & 0.4 & $0.9(0.6-1.3)$ & 0.530 \\
\hline Co-morbidity influenced choice of antimalarial medicine? & $161(57.7)$ & $118(42.3)$ & 2.4 & $1.5(0.9-2.3)$ & 0.120 \\
\hline Patients' test results influenced choice of medicine & $207(58.6)$ & $146(41.4)$ & 3.05 & $1.86(1.0-3.6)$ & 0.080 \\
\hline Patients' ability to pay influenced antimalarial medicine given? & $113(54.1)$ & $96(45.9)$ & 6.71 & $1.7(1.2-2.6)$ & $0.009^{*}$ \\
\hline Treatment influenced by ACT advertisement & $86(65.2)$ & $46(34.8)$ & 2.6 & $0.7(0.4-1.1)$ & 0.110 \\
\hline Medicines availability influenced drugs received by patients & $188(57.1)$ & $141(42.9)$ & 7.1 & $2.0(1.3-3.9)$ & $0.007^{*}$ \\
\hline Government-approval influenced choice of antimalarial medicine & $227(59.7)$ & $153(40.3)$ & 0.7 & $1.6(0.7-4.0)$ & 0.390 \\
\hline Route of administration influenced choice of antimalarial medicine? & $149(55.2)$ & $121(44.8)$ & 8.6 & $2.0(1.3-3.1)$ & $0.003^{*}$ \\
\hline Previous training on malaria diagnosis and treatment guidelines & $122(55.7)$ & $97(44.3)$ & 1.6 & $1.0-2.4$ & $0.039^{*}$ \\
\hline Good knowledge of malaria case management & $84(41.6)$ & $118(58.4)$ & 5.4 & $3.4-8.3$ & $<0.001^{*}$ \\
\hline
\end{tabular}


Table 5 Predictors of Preference for ACT among healthcare providers, Lokoja, North-Central Nigeria

\begin{tabular}{llll}
\hline Characteristics & Adjusted OR & $95 \% \mathrm{Cl}$ & $p$-value \\
\hline Medicines availability influenced drugs received by patients & 1.2 & $0.6-2.4$ & - \\
Patients' ability to pay influenced drug treatment & 1.5 & $0.9-2.4$ \\
Ever trained on guidelines** & 2.3 & - & $1.4-3.7$ \\
& & - & 0.120 \\
Healthcare provider other than doctors & 0.5 & $0.3-1.0$ & $0.008^{*}$ \\
$<5$ duration of practice (years) & 0.7 & $0.4-1.3$ & 0.052 \\
Good Healthcare providers' knowledge of guidelines & 4.0 & $2.4-6.7$ & 0.053 \\
\hline
\end{tabular}

*Significant at $p<0.05$

**Guidelines for diagnosis and treatment of malaria

who usually refer clients to laboratory test. The use of malaria rapid diagnostic test (mRDT) recommended for informal sector including PPMVs is still not well established in Nigeria and was not promoted until recently [15]. Since the PPMVs do not have correct knowledge of diagnostics especially mRDT which is required for prescribing ACT, they are not likely to prefer ACT for treatment of malaria. This high level of ignorance is of concern because healthcare providers who do not know malaria confirmatory tests may not request for such test and could continue presumptive and unnecessary treatment of unconfirmed fevers with attendant wastes of financial resources in a low income country and increasing the risk of parasite developing resistance to antimalarial drugs.

Physicians constituted the highest proportion of healthcare providers with good knowledge of malaria diagnosis and treatment, possibly because physicians undertake mandatory continuing medical education, a requirement for renewal of their annual practicing licenses. The PPMVs are uniquely wide spread, accessible and of varied basic educational qualification [16]. Though PPMVs had largest proportion of trained respondents, they constituted the least proportion of respondents with good knowledge of malaria case management, which suggests that training alone might not be sufficient for achieving good knowledge. While the formal healthcare providers such as physicians and nurses have better opportunity of comprehensive in-service training, the informal sector though may have training, many of these are of lower quality because their lower level of education is always taking into consideration and the training focuses strictly on the services they are legally authorized to provide $[14,17]$. The fact that PPMVs contributed the least to respondents with good knowledge of malaria case management also highlights a need for supportive supervision to aid knowledge retention, minimize irrational use of malaria medicines and poor treatment outcomes [14] after initial training.
Preference for ACT and factors associated with preference for ACT

Overall, preference for ACT among healthcare providers was 39.6\%. Physicians: 50 (67.6\%), pharmacists: 7 (59.3\%) CHOs: 5 (55.6\%), CHEWS: 16 (41.0\%), nurses: 56 (37.8\%) and PPMV: 24 (19.8\%) had PFA. It is worrisome that twelve (12) years after Nigerian government approved ACT for treatment of uncomplicated malaria, overall preference for ACT was below average, a situation which can be improved by implementation of subsidy schemes [18, 19] to lower prices and encourage preference for ACTs as cost and ability to pay are a key considerations in the choice of antimalarial drugs to prescribed as demonstrated in this study [20]. The $\mathrm{ACTs}$ are more expensive than the older antimalarial drugs.

Pharmaceutical companies advertise malaria medicines during clinical meetings of physicians. Though advertising medicines is associated with preference for such medicines [21], we did not find such association probably because more than eighty (80) percent of our respondents were non-physicians, who are not frequently exposed to such advertisements.

Training improves preference for ACT and quality of malaria treatment [22, 23]. This study has shown that training of healthcare providers independently predicted preference for ACT and that training outcomes depend on the cadre trained [24]. However, training alone does not automatically result in preference for ACT. For instance, out of $65.8 \%$ PPMVs trained, only $19.8 \%$ preferred ACT which suggests influence of barriers to behavior change and profit motive might have influenced preference for ACTs among PPMVs [8].

A limitation of this study was that the researchers did not review all past 'prescriptions' by respondents to corroborate written preferences for ACT in vignettes. However, a follow-up question requested 
respondents to write down names of medicines they used to treat malaria in their health facilities.

\section{Conclusion}

Overall preference for ACT among healthcare providers was low(39.6\%) while preference for ACTs and proportion of health workers with good knowledge of Malaria Case Management were even lower among PPMVs. Predictors of preference for ACT were being trained on and having good knowledge of malaria case management. However, effect of such training depended on cadre trained while having good knowledge of malaria case management alone was insufficient predictor of preference for ACT. We recommend evaluation of current training quality with emphasis on laboratory component of training, follow-up supportive supervision of PPMVs and behavior change communication on ACT use.

\section{Abbreviations}

AFENET: African Field Epidemiology Network; CDC: United States Centers for Disease Control; CHEWs: Community Health Extension Workers; CHOs: Community Health Officers; MCMT: Malaria Case Management Training; mRDT: Malaria rapid diagnostic test (mRDT); PFA: Preference For Artemisinin-based Combination Therapy; PHCs: Primary Healthcare Centers; PPMVs: Patent and Proprietary Medicine Vendors

\section{Acknowledgements}

The authors acknowledge the contribution of Dr. Kazeem Ayankola and entire staff of the United States President's Malaria Initiative/Malaria Action Program for States project, Kogi State, for facilitating contact with heads of health facilities and Dr. Ejeh, Director Medical Services and Training at the Kogi State Ministry of Health for his guidance on getting ethical approval for the study. We also appreciate the Medical Directors of Federal Medical Center and Specialist Hospital, Lokoja for providing list of staff in their health facilities. We acknowledge the cooperation and support of leadership and management of the Kogi State Ministry of Health, Primary Healthcare Department of Lokoja Local Government Area, Federal Medical Centre, staff of all health facilities, and patent and proprietary medicine vendors. We appreciate Mr. Demola Ogunlabi of the Department of Epidemiology and Medical Statistics for always obliging us with information from the University of Ibadan and the research assistant, Engineer Yakubu Danmusa for his dedication and commitment.

We acknowledge the cooperation and patience of our study participants who gave consent and took part in the study even when there were no immediate benefits of participating in the study. We appreciate Engineer Yakubu Rabiu Danmusa for his useful comments in data entry and editing. Our sincere gratitude to African Field Epidemiology Network and the United States Center for Disease Control and Prevention (AFENET/US CDC for providing financial support for printing, production, transportation and other logistics of the study.

\section{Funding}

This study was supported by cooperative agreement number U2R6H000046 funded by the Center for Disease Control and Prevention (CDC) through the Nigeria Field Epidemiology and Laboratory Training Programme. The funders had no role in the conceptualisation, design, data collection, analysis and interpretation and writing of the manuscript.

\section{Availability of data and materials}

The datasets used and/or analysed during the current study are available from the corresponding author on reasonable request.

\section{Authors' contributions}

SW: conceptualized and designed the study, collected, analysed and interpreted the data, and wrote draft manuscript. OA: contributed immensely to study design, interpretation of findings, initial drafting, final revision and formatting of manuscript. DD, BA, PA, PN, SG and MS: contributed to data analysis and revision of the manuscript. IA: Supervisor and contributed immensely to study design, interpretation of findings, extensive revision and formatting of manuscript. All authors read and approved the final manuscript.

\section{Ethics approval and consent to participate}

Ethical approval for this study was obtained from the Kogi State Ministry of Health, Kogi State Specialist Hospital and Federal Medical Centre, Lokoja, Kogi State. We maintained confidentiality and obtained written informed consent from all participants who were given an option of voluntary withdrawal of their participation at any stage of the study without sanctions or penalty.

\section{Consent for publication}

This is not applicable

\section{Competing interests}

The authors declare that there are no competing interests.

\section{Author details}

${ }^{1}$ Division of Health Promotion, Department of Family Health, Federal Ministry of Health, Abuja, Nigeria. ${ }^{2}$ Nigeria Field Epidemiology and Laboratory Training Programme, Abuja, Nigeria. ${ }^{3}$ African Field Epidemiology Network, Nigeria Country Office, Abuja, Nigeria. ${ }^{4}$ Department of Epidemiology and Medical Statistics, University of Ibadan, Ibadan, Nigeria. ${ }^{5}$ Liberia Field Epidemiology Training Programme, Monrovia, Liberia.

Received: 30 January 2018 Accepted: 18 December 2018 Published online: 19 January 2019

\section{References}

1. Zhou L-J, Xia J, Wei H-X, Liu X-J, Peng H-J. Risk of drug resistance in Plasmodium falciparum malaria therapy - a systematic review and metaanalysis. Parasitol Res. 2017;116(2):781-8. https://doi.org/10.1007/s00436-0165353-2 http://www.ncbi.nlm.nih.gov/pubmed/28028628.

2. National Population Commission (NPC) [Nigeria] and ICF International. Nigeria Demographic and Health Survey 2013. Abuja, Nigeria, and Rockville, Maryland: NPC and ICF International; 2014. Available from: https://dhsprogram.com/pubs/pdf/fr293/fr293.pdf

3. Eve S, Samba D, Benoît D, Diawara SI, Seidina D, Saibou D, et al. Evaluation of the quality of prescription and dispensing of artemisinin-based therapeutic combinations in the Bamako District. Mali Mali Med. 2010;25(3): 31-40 http://www.ncbi.nlm.nih.gov/pubmed/21441091.

4. Oguche S, Okafor HU, Watila I, Meremikwu M, Agomo P, Ogala W, et al. Efficacy of Artemisinin-based combination treatments of uncomplicated falciparum malaria in under-five-year-old Nigerian children. Am J Trop Med Hyg. 2014;91(5):925-35 http://www.ajtmh.org/cgi/doi/10.4269/ajtmh.13-0248.

5. Adeneye AK, Jegede AS, Mafe MA, Nwokocha EE. Awareness of antimalarial policy and use of artemisinin-based combination therapy for malaria treatment in communities of two selected local government areas of Ogun state. Nigeria World Health Popul. 2014;15(1):45-60 http://www.ncbi.nlm.nih. gov/pubmed/24702765.

6. O'Connell KA, Gatakaa H, Poyer S, Njogu J, Evance I, Munroe E, et al. Got ACTs? Availability, price, market share and provider knowledge of anti-malarial medicines in public and private sector outlets in six malaria-endemic countries. Malar J. 2011;10(1):326 http://www.ncbi.n/m.nih.gov/pubmed/22039838.

7. Uzochukwu BS, Chiegboka LO, Enwereuzo C, Nwosu U, Okorafor D, Onwujekwe $\mathrm{OE}$, et al. Examining appropriate diagnosis and treatment of malaria: availability and use of rapid diagnostic tests and artemisinin-based combination therapy in public and private health facilities in south East Nigeria. BMC Public Health. 2010;10(1):486 http://www.ncbi.nlm.nih.gov/ pubmed/20712876

8. Mangham-Jefferies L, Hanson K, Mbacham W, Onwujekwe O, Wiseman V. What determines providers' stated preference for the treatment of uncomplicated malaria? Soc Sci Med. 2014;104:98-106 http://www.ncbi.nlm.nih.gov/pubmed/24581067.

9. Ibrahim MK, David JM, Shaibu UM. Malaria and agriculture: examining the cost implications and effect on productivity among farm households in Kogi state, Nigeria. International Journal of TROPICAL DISEASE \& Health. 
2017;23(3):1-9 Available from: http://www.journalrepository.org/media/ journals/JTDH_19/2017/Jun//brahim2332017IJTDH33730.pdf.

10. Igboeli NU, Ukwe CV, Ekwunife OI. Increasing use of artemisinin-based combination therapy for treatment of malaria infection in Nigerian hospitals. Pharm Pract (Granada). Centro de Investigaciones y Publicaciones Farmaceuticas. 2010;8(4):243-9 http://www.ncbi.nlm.nih.gov/pubmed/ 25126148.

11. Ndibuagu EO, Amadi OF, Ugwu ET. Knowledge and perception of malaria rapid diagnostic test among medical doctors in a south eastern Nigeria tertiary hospital. Journal of Biosciences and Medicines. 2017;5:1-16 Available from: https://file.scirp.org/pdf/JBM_2017102015495898.pdf.

12. Uzochukwu BSC, Chiegboka LO, Enwereuzo C, Nwosu U, Okafor D, Onwujekwe OE, Uguru NP, Sbeudu FT, Ezeoke OP. Examining appropriate diagnosis and treatment of malaria: availability and use of rapid diagnostic tests and Athemisinin-based combination therapy in public and private health facilities in Southeast Nigeria. BMC Public Health. 2010;10:486 https://doi.org/10.1186/1471-2458-10-486.

13. Usman R. Factors influencing utilisation of malaria rapid diagnostic tests among healthcare workers in Zamfara State. A dissertation submitted to the Ahmadu Bello University, Zaria Nigeria toward MPH degree. 2017.

14. Beyeler N, Liu J, Sieverding M. A systematic review of the role of proprietary and patent medicine vendors in healthcare provision in Nigeria. PLoS One. 2015;10(1):e0117165 http://www.ncbi.nlm.nih.gov/pubmed/25629900.

15. Odugbemi B, Ezeudu C, Ekanem A, Kolawole M, Akanmu I, Olawole A, et al. Private sector malaria RDT initiative in Nigeria: lessons from an end-of-project stakeholder engagement meeting. Malar J. 2018;17:70 https://doi.org/10.1186/s12936-018-2222-8.

16. Liu J, Prach LM, Treleaven E, Hansen M, Anyanti J, Jagha T, Seaman V, Ajumobi $\mathrm{O}$, Isiguzo $\mathrm{C}$. The role of drug vendors in improving basic health-care services in Nigeria. Bull World Health Organ. 2016;94:267-75 www.who.int/bulletin/volumes/94/4/15-154666/en/.

17. Oshiname FO, Brieger WR. Primary care training for patent medicine vendors in rural Nigeria. Social science and medicine. 1992;35(12):147771484 Available from: https://www.ncbi.nlm.nih.gov/pubmed/1485195.

18. Ezenduka CC, Ogbonna BO, Ekwunife Ol, Okonta MJ, Esimone CO. Drugs use pattern for uncomplicated malaria in medicine retail outlets in Enugu urban, Southeast Nigeria: implications for malaria treatment policy. Malar J. 2014;13:243 http://www.ncbi.nlm.nih.gov/pubmed/24961280.

19. Tougher S, Ye Y, Amuasi JH, Kourgueni IA, Thomson R, et al. Effect of the affordable medicines facility-malaria (AMFm) on the availability, price, and market share of quality-assured artemisinin-based combination therapies in seven countries: a before-and-after analysis of outlet survey data. Lancet. 2012; 380:1916-26 https:/www.thelancet.com/journals/lancet/article/PIIS0140.

20. Palafox B, Patouillard E, Tougher S, Goodman C, Hanson K, Kleinschmidt I, et al. Understanding private sector antimalarial distribution chains: a crosssectional mixed methods study in six malaria-endemic countries. PLoS One. 2014;9(4):e93763 https://doi.org/10.1371/journal.pone.0093763.

21. Bamiselu OF, Ajayi I, Fawole O, Dairo D, Ajumobi O, Oladimeji A, et al. Adherence to malaria diagnosis and treatment guidelines among healthcare workers in Ogun State. Nigeria. BMC Public Health. 2016;16(1): 828 Available from: http://bmcpublichealth.biomedcentral.com/articles/10. 1186/s12889-016-3495-x.

22. Okeke T, Uzochukwu BSC. Improving childhood malaria treatment and referral practices by training patent medicine vendors in rural south-East Nigeria. Malaria J. 2009;8:260 https://malariajournal.biomedcentral.com/ articles/10.1186/1475-2875-8-260

23. Jefferies, LMM. Providers knowledge, preference and practice in treating patients with suspected malaria in Cameroon and Nigeria. PhD (research paper style) thesis, London School of Hygiene \&Tropical Medicine. 2014. doi https://doi.org/10.17037/PUBS.02603692

24. Aung T, Longfield K, Aye NM, San AK, Sutton TS, Montagu D, et al. Improving the quality of paediatric malaria diagnosis and treatment by rural providers in Myanmar: an evaluation of a training and support intervention. Malar J. 2015;14(1):397 http://www.ncbi.nlm.nih.gov/pubmed/26450429.

Ready to submit your research? Choose BMC and benefit from:

- fast, convenient online submission

- thorough peer review by experienced researchers in your field

- rapid publication on acceptance

- support for research data, including large and complex data types

- gold Open Access which fosters wider collaboration and increased citations

- maximum visibility for your research: over $100 \mathrm{M}$ website views per year

At BMC, research is always in progress.

Learn more biomedcentral.com/submissions 